\title{
Ethnosyntax: Introduction
}

\author{
N. J. ENFIELD
}

Grammar is thick with cultural meaning. Encoded in the semantics of grammar we find cultural values and ideas, we find clues about the social structures which speakers maintain, we find evidence, both historically relevant and otherwise, of the social organization of speech communities. We find complex morphosyntactic systems, such as honorific inflection and agreement in Japanese, dedicated to the expression of social deixis (Prideaux 1990; Shibatani 1990). We find systems of nominal classification encoding a range of distinctions of cultural importance, their very existence possibly even revealing the kind of society speakers maintain (Craig 1986). We find that variation in the grammatical resources used within a single social system is sensitive to fundamental sociocultural distinctions such as gender and kinship relations, as observed in the sometimes extensive differences in grammar of men's and women's speech (Dunn 2000), or in the grammar of auxiliary languages such as 'avoidance styles' (Dixon 1971). We find different grammatical systems coexisting and interacting in culturally mediated ways, as in situations of diglossia, bilingualism, and code-switching arising from complex social conditions (Ferguson 1964: 433; Gumperz and Wilson 1971). We find grammatical constructions directly encoding cultural values of a given group of speakers, as for example in a range of grammatical devices in Russian expressing 'emotionality', 'non-rationality', 'non-agentivity', and 'moral passion' (Wierzbicka 1992).

This list of ways in which culture is entwined in grammar could go on and on (for a smorgasbord of examples, see Hymes 1964). It is intended that 'ethnosyntax' - broadly defined as the study of connections between the cultural knowledge, attitudes, and practices of speakers, and the morphosyntactic resources they employ in speech-should encompass this diverse range of grammar-culture effects. This field of research asks not just how culture and grammar may be connected, but also how they may be interconstitutive, through overlap and interplay

For generous and helpful comments on various drafts of this Introduction, I am grateful to the following people: Penny Brown, Kate Burridge, Tony Diller, Dominique Estival, Nick Evans, Helen Fraser, Cliff Goddard, Geoffrey Haig, Randy LaPolla, Penny Lee, Steve Levinson, Chris Manning, Andy Pawley, Alastair Pennycook, Alan Rumsey, Gunter Senft, Jane Simpson, Catherine Travis, Anna Wierzbicka, an anonymous referee (R2), and, especially, another anonymous referee (R1). I also acknowledge helpful input from Melissa Bowerman, Bill Foley, John Lucy, and David Wilkins. None are responsible for shortcomings. 
between people's cultural practices and preoccupations and the grammatical structures they habitually employ. This may make reference to the semantics of grammar, or to ways in which the use or productivity of grammatical resources are constrained or licensed by culture.

This introductory chapter has two aims: first, to identify the range of ethnolinguistic phenomena treated in various contributions to this volume (without aiming to survey the potential scope of ethnosyntax as a field of research); and second, to discuss a number of methodological and theoretical issues of importance to research on the grammar-culture interface. The chapter is structured as follows. Section 1.1 provides brief background on selected work directly relevant to the focus of this book. Section 1.2 discusses a range of phenomena which come under the rubric of 'ethnosyntax', and which are dealt with in various contributions to the volume. An initial distinction, referred to by a number of contributors (e.g. Goddard, Rumsey, and Simpson), is between 'narrow' and 'broad' senses of the term. The 'narrow sense' refers to the direct encoding of cultural meaning in the semantics of morphosyntax - i.e. where a semantic explication of a grammatical construction could reveal a 'cultural script' (Wierzbicka, this volume). The 'broad sense' encompasses a much wider range of possible relations between grammar and culture, including semantic and pragmatic consequences of 'typicality' (as culturally defined), socially indexical significance of grammatical choices, culturally determined patterns of use of certain grammatical features, and interaction between culture and grammatical description. Phenomena which bridge the 'broad' and 'narrow' categories, and which may even provide an explanatory link between them, involve the role of culture in semantic and grammatical change.

Fundamental questions of theory and methodology inevitably arise when one attempts to demonstrate links between grammar and culture, and these are discussed in Section 1.3. The two main problems are, first, settling on methods of describing grammar and culture, and second, finding independent support for putative grammar-culture links.

Finally, Section 1.4 gives a brief overview of the volume, and Section 1.5 concludes.

\subsection{BACKGROUND}

Many have intuited that there is a connection between linguistic structures on one hand, and patterns of thought of speakers, on the other. ${ }^{1}$ Patterns of thought are seldom clearly separated in that literature from patterns of culture, given that for many, culture is defined as collective patterns of thought. Thus, for Sapir (1994:

\footnotetext{
${ }^{1}$ Important sources include Boas 1911, Sapir 1949, 1994, Hoijer 1953, 1964, Whorf 1956, Lee 1959, Hymes 1961, 1964, 1966, Mathiot 1964, Landar 1966, Blount 1974, Hale 1986, Grace 1987, Rumsey 1990, Hill and Mannheim 1992, Lucy 1992a, Wierzbicka 1992, D'Andrade 1995, Gumperz and Levinson 1996, Lee 1996, Duranti 1997, Foley 1997, Pütz and Verspoor 2000, Niemeier and Dirven 2000 , among others.
} 
36), for example, it is consensus and sanction with regard to the meanings of things that defines culture. Sapir adopted the then emerging American structuralist approach to grammatical description, ascribing a greater and more complex order to the systematic structuring in language of human experience (cf. Sapir 1949). Like Boas before him, Sapir recognized that there may be influence of culture upon language. He later stressed that culture was not about 'what people did' per se, but about the meaning of what they did (Sapir 1994). Further, like Boas, Sapir saw the influences of culture on language as being mostly in the lexicon, and less in the grammar. An extensive literature in ethnosemantics has since explored this area (see D'Andrade 1995 and references therein).

Whorf (1956) took further the notion that language could influence habitual patterns of thought, stressing the systematic relationship between language and cognition, and putting forward his 'principle of linguistic relativity', by which 'users of markedly different grammars are pointed by the grammars toward different types of observations', thus arriving at 'somewhat different views of the world' (Whorf 1956: 221). Exactly what Whorf intended has been a matter of discussion ever since (Lucy 1992a; Gumperz and Levinson 1996; Lee 1996, 2000; Goddard in press), and how this relates specifically to 'culture', rather than 'thought' per se, remains open to interpretation. ${ }^{2}$ Whorf's work is important in the context of this book, since it was Whorf who turned attention to the more subtle realms of morphosyntax.

There is abundant literature describing past and present approaches to the relationship between grammar and culture (see n. 1), and no review is necessary here. In the rest of this section, I restrict discussion to two important authors on the grammar-culture relationship-Anna Wierzbicka and Ken Hale-who have largely been overlooked in recent reviews.

Wierzbicka (1979) coined the term 'ethnosyntax', using it exclusively in the 'narrow' sense (see s. 1.2.1 below). She claimed that it is possible to show 'in a rigorous and verifiable way' that 'every language embodies in its very structure a certain world view, a certain philosophy' (Wierzbicka 1979: 313). ${ }^{3}$ Rather than focusing on 'a few arbitrary lexical items', she examined grammatical constructions, arguing that '[s]ince the syntactic constructions of a language embody and codify certain language-specific meanings and ways of thinking, the syntax of a language must determine to a considerable extent this language's cognitive profile' (Wierzbicka 1979: 313; see s. 1.2.1 below). Wierzbicka's work is conspicuously absent from the otherwise excellent recent reviews of linguistic anthropology referred to above. Many scholars are put off by a simple universalist claim at the heart of her approach-namely, that all languages have a directly translatable primitive semantic core, and it is at this level that linguistic and cultural analysis

\footnotetext{
2 Note the primacy assigned to culture in a recent definition of linguistic relativity as 'the idea that culture, through language, affects the way we think' (Gumperz and Levinson 1996: 1).

${ }^{3}$ Wierzbicka's work on ethnosyntax is discussed in detail in this volume, with reference to a number of examples, by Cliff Goddard. Thus, I do not discuss details in this introduction.
} 
is to be done. But to ignore her work on this basis is unjustified. One may refrain from making the same theoretical commitments, yet still engage with the rich and careful descriptions of grammar and culture that Wierzbicka has produced over more than twenty years (see Wierzbicka 1979, 1988, 1991, 1992, 1997, 1998).

A second researcher of importance to the theme of this volume is Ken Hale, whose 1966 paper 'Kinship reflections in syntax' inspired an important body of research on 'kin-tax' in Australian languages, not often referred to outside specialist contexts (Hercus and White 1973; Heath, Merlan, and Rumsey 1982; Dench 1987; Wilkins 1988, 1993). The purpose of Hale's paper was to show that principles of kinship organization, which are of course firmly within the realm of culture, can and do play a role in syntactic rules. He showed with evidence from Arrernte and Lardil that agnation (i.e. patrilineal descent) and generation harmony (a relationship holding between those of alternate, but not adjacent, generations) are referred to in the 'structural description' of a syntactic rule of compound nounphrase reduction. He concluded as follows (Hale 1966: 324):

It is not unusual among the languages of the world for the grammatical apparatus devoted to personal deixis to mark categories relating to sociologically defined notions. Also, given the importance of classificatory kinship in Australian societies, it is not surprising to find that certain central features of the kinship system are reflected in the pronominal paradigm. This being so, it is reasonable to expect that a syntactic rule which mentions pronominal categories in its structural description might also make reference to one or more aspects of the kinship system. As we have seen, this expectation is correct

A later study (Hale 1986) looks at the relationship between semantic categories and two distinct senses of 'world view'. Hale's 'World View-1' refers to 'the central propositions or postulates in a people's theory of how things are in the world' (Hale 1986: 233), and Hale stresses that these cultural 'propositions' are established independent of language. Nevertheless, relationships between 'World View -1' and language can be found. (See s. 1.3.5 below for further discussion of Hale's position.) Hale describes 'two fundamental themes in Warlpiri philosophy' - the 'eternal logic' (the logic of 'cyclical perpetuity, or unbroken circles', including themes such as the 'persistence of entities through transformation' and the 'unity of the actual and the potential') and the 'logic of complementarity' (or the 'unity of the opposites'). He then attempts to 'relate [these themes] to aspects of the Warlpiri language' (Hale 1986: 235), giving a range of supporting examples in lexical and grammatical semantics, including 'actual/ potential' metonymy (O'Grady 1960; Evans 1997), distinctive ways of referring to manufacture (not as 'making' but as 'transforming' or 'fixing'), themes in sacred myth, aspects of kinship nomenclature, and patterns of antonymy.

Hale's 'World View-2' is defined as 'the "analysis of phenomena" embodied in the system of lexico-semantic themes or motifs which function as integral components in a grammar' (Hale 1986: 234), and which is therefore common to all speakers of the language. Warlpiri speakers, qua speakers of Warlpiri, elaborate 
a 'fundamental theory of relations' (p. 242), involving 'the definition of spatial, temporal, and identity relations in terms of "central" versus "non-central" (or "terminal") coincidence' (p. 238). This abstract theme in the world view of Warlpiri speakers 'manifests itself in the meanings of certain grammatical elements' in the language (p. 238). Hale provides data from 'six areas of Warlpiri grammar'-local cases, directional enclitics, finite complementizers, infinitival complementizers, tense/aspect markers, and depictive and translative predicates-concluding that 'a fundamental abstract semantic opposition of central versus non-central coincidence is at work' and that 'it is to be observed with particular clarity and purity in the grammar of Warlpiri' (Hale 1986: 252). I refer the reader to Hale's paper for data and detailed discussion.

\subsection{FORMS OF ETHNOSYNTAX: A RANGE OF CULTURE-GRAMMAR CONNECTIONS}

To cover the full scope of candidates for ethnosyntax phenomena would be beyond the limits of this introductory chapter, and probably premature. It is hoped that this book may lead to further efforts in defining the range of phenomena which may come under the ethnosyntax rubric. This part focuses largely on phenomena which are discussed in contributions to this volume, beginning with a distinction between 'narrow' and 'broad' senses of the term 'ethnosyntax', the former corresponding to Wierzbicka's original sense, the latter having a broadened and more diverse scope. After discussion of a number of distinct 'broad sense' phenomena, the section finishes with a discussion of language change, in which a linkage between 'broad' and 'narrow' senses of ethnosyntax can be observed.

\subsection{1. 'Narrow' and 'broad' senses of ethnosyntax}

Wierzbicka's original sense of the term 'ethnosyntax' refers to the direct encoding of cultural ideas in the semantics of morphosyntax, and this is referred to here as ethnosyntax in the 'narrow' sense. This 'narrow sense' does not include any grammatical phenomenon in which a semantic analysis would not reveal some 'statement' of a notion specific to the culture of speakers. For example, in the present volume, Wierzbicka argues that the semantics of certain English causative constructions embody primary Anglo values of independence and autonomy in personal interaction. Elsewhere, she has argued that important cultural values of Russian speakers are encoded directly in a host of grammatical devices such as diminutives, infinitive constructions, and reflexive constructions (Wierzbicka 1992: ch. 12). Her original work on 'ethno-syntax' (Wierzbicka 1979) includes a masterful study of subtle variations of semantic detail in grammatical constructions encoding 'bodily actions and events' in a number of European languages, as well as Japanese. Semantic analyses of different languages reveal different 'philosophies' regarding the involvement of individuals in bodily events and actions. 
Similarly, but from a different descriptive tradition, Langacker (1994) has argued that 'direct symbolization of culture-specific conceptions' can be found in grammatical devices. Based on his view of grammatical semantics fundamentally centring on experientially based prototypes, Langacker claims that while cognitive models that come into play in prototype semantics 'are themselves quite abstract, and may in large measure be universal and pre-cultural', it remains 'evident that cultural factors play some role in either shaping the models or determining their extension to non-prototypical instances' (Langacker 1994: 44; cf. Lakoff 1987; Newman 1996, this volume; Palmer 1996). He gives examples (from Tuggy 1979) of honorific meanings encoded in Tetelcingo Nahuatl morphosyntax, and cites a 'controlled' versus 'uncontrolled' distinction in Chipewyan classificatory verb stems which is 'claimed to have a larger cultural relevance' for speakers (Rushforth and Chisholm 1991; cf. Rice 1998; Newman, this volume).

Going beyond examples of this kind, there are 'broad sense' phenomena. These include morphosyntactic categories and constructions which do not themselves encode culture-specific 'statements' in their semantics, but which may nevertheless show culture-specific patterns of distribution and use, or other culture-related effects. Morphosyntactic devices which are not necessarily culture-specific in semantic terms - such as switch-reference systems and classifier constructionsmay nevertheless be used differently, where those differences have culture-specific motivations. Thus, culture-specific uses of such non-culture-specific devices may relate to the pragmatic effects of different 'cultural premisses' (Enfield, this volume), or to culture-specific semantics of the lexical items involved. ${ }^{4}$

We now turn to some 'broad sense' phenomena which are treated in contributions to this volume, namely 'typicality' effects, the social indexicality of grammatical choices, and the effects of cultural institutions taking an interest in grammar.

\subsubsection{Typicality effects}

Repeated experiences of complex phenomena result in typifications (Schutz 1970) or schemas/frames/scenarios (Holland and Quinn 1987), which may guide our interpretations of the semantics of complex grammatical constructions. My own contribution to this volume takes as its starting point an observation made in literature on verb serialization (Durie 1997; Bruce 1988), that certain combinations of morphemes in serial constructions are deemed by speakers to be unacceptable, not because they are anomalous in some structural way, but because they describe events which do not qualify as 'event types'. The most interesting feature of this interplay between grammar and culture is not the apparent inadmissibility of certain combinations, but the overall semantic behaviour of the complex constructions. When certain combinations are culturally typical, they can become enriched metonymically, evoking the default details defined by a given culturally normal

\footnotetext{
${ }^{4}$ David Wilkins has suggested distinctions along these lines in correspondence with contributors to this book. See contributions by Goddard and Rumsey for further discussion.
} 
event type. This corresponds to the principle in Gricean pragmatics whereby one does not mention details wherever details need not be mentioned (Grice's 'Maxim of Quantity No. 2', 1975: 45; Levinson's 'I-Principle', 2000: 37). Thus, given two scenes of equivalent objective/perceptual complexity, but of different typicality status, speakers produce descriptions of different morphosyntactic complexity.

Constructions showing certain levels of syntactic, and therefore conceptual, complexity are more usually acceptable (i.e. considered more 'grammatical') when they describe culturally typical or easily imaginable scenarios. Thus, the former of the following sentences is more acceptable, and certainly more easily processed: ${ }^{5}$

(a) Did you hear that the guy who the police were looking for's red Cortina got stolen?

(b) Will they deny that a nun who your shopkeeper was chatting up's large settee got replicated?

Clark and Malt (1984: 203) similarly point out that in comprehension of a hardto-process utterance, if a certain meaning seems highly likely to be intended in the context, then one is likely not to bother going through with fully resolving the difficult processing task. They give the example of Wason and Reich's (1979) 'verbal illusion' No head injury is too trivial to ignore, and point to the background assumptions or 'heuristic procedures' used in figuring out what 'must' be meant. It can take a while to figure out that this sentence means 'All head injuries are to be ignored, including the most trivial ones'. What is not explicitly discussed in such accounts is that these heuristics are often cultural (Levinson 1995: 240; Enfield 2000a: 39), and that describing them is a matter of ethnography.

Langacker (1994) discusses the problem of culture-related constraints on accessibility to morphosyntactic resources under the heading of 'distributional impact of cultural knowledge', by which 'a specific cultural practice or belief motivates the otherwise unexpected membership of some entity in a conceptually grounded category of grammatical significance' (Langacker 1994: 39). He argues that 'quite a number of grammatical phenomena are in one way or another sensitive to cultural expectations. They somehow reflect culturally determined conceptions of what constitutes a familiar scenario, a canonical situation, or a normal course of events' (Langacker 1994: 39-40, original emphasis). Langacker (1994) discusses one example concerning the distribution of verb stems in Cupeño (Uto-Aztecan). He reports Hill's (1969) argument that verbs in the 'zero stem' class (as opposed to those that take either the -in suffix or the -yax suffix) make 'natural' predications, describing 'the normal behaviour of animals, plants, inanimate objects, and the weather', '[most] natural processes, as well as states of mind', and the everyday activities which Hill describes as 'good solid Cupeño cultural behaviour' (1969: 352)-these include 'make acorn mush', 'make a basket', 'shoot arrows', and

\footnotetext{
${ }^{5}$ I thank Avery Andrews for pointing this out.
} 
'relate tribal history'. Langacker (1994: 43) also discusses violations of the 'coordinate structure constraint' in English (e.g. What did Bill go to the store and buy?), which are permissible when the underlying 'scenario' instantiates the 'natural course of events' (Lakoff 1986: 153) (unlike, say *What did Sally mow the lawn and fix?). Similar is the contrast between definite articles and 'zero articles' in expressions like She went to (the) school/church/university/bed/hospital/sea/town/ etc. (Levinson 2000: 147). Presence of the article results in a simple 'go to goal of motion' reading, while ellipsis of the evokes a much richer culturally defined scenario in each case (compare John went to prison versus John went to the prison).

Another case of typicality having an effect on grammar is the common restriction on productivity of noun incorporation. The constraint on using certain nounverb combinations in incorporating structures relates to the cultural 'normalness' of the concepts (signified by the given noun and verb) being routinely associated in daily life. Mithun gives an example from Chukchi, in which 'fuel-gathering, wood-cutting, and tent-breaking' are 'unitary, name-worthy activities' which appear in noun-incorporating compounds, yet 'brushwood-plucking, boat-loading, and tent-loading are not, so they are expressed by separate V's and N's' (Mithun 1984: 861).

A final example concerns an apparently increased tolerance for 'extensions' beyond the strict semantic specifications of certain productive grammatical constructions in cases where the extension is 'licensed' by a culturally provided scenario. For example, in English, a clash between the direct causation suggested by the frame ' $\mathrm{V} \mathrm{NP}$, OFF $\mathrm{NP}_{2}$ ' and indirect causation in a scene being described is tolerated when the scenario is 'licensed' by virtue of being a culturally established one-thus, one may be booed off the stage, but not *idgeted off the stage. ${ }^{6}$

Constraints in the productivity and interpretation of morphosyntactic devices, contingent upon the 'normal course of events' as culturally defined, are evidently widespread and pervasive. However, they have not so far been the focus of concentrated cross-linguistic research (see Enfield, this volume).

\subsubsection{Social indexicality and 'emblematicity' of grammar}

Productive morphosyntactic features can have conscious cultural value, such that mastery in use is encouraged and deliberately maintained for aesthetic or other cultural reasons. ${ }^{7}$ Examples include grammatical structures with expressive or creative import, such as expletive infixation in Australian English (fan-bloody-tastic), or the productive systems of expressive rhyming reduplication found across languages of mainland South-East Asia (Diffloth 1979). In Lao, for example,

\footnotetext{
6 I thank Melissa Bowerman for pointing this out.

${ }^{7}$ On the level of whole systems, diglossia (Ferguson 1964) is a good example - the ability of some speakers to handle the 'high' register better than other speakers can correlate with significant social facts.
} 
there is a pattern of expressive reduplication involving complex rules of reduplication and vowel mutation (e.g. where nam ${ }^{0}$.hòòm ${ }^{3}$ 'perfume' derives nam ${ }^{0}$.hòom ${ }^{3}$ nam $^{0}$. hèm $^{3}$ 'perfume and that sort of stuff'). This is a productive grammatical system which all Lao speakers are aware of and can recognize and comprehend. And unlike, say, the verbal tense-aspect-modality system, not all speakers have equal command of expressive morphosyntax, and indeed individual skill in using it is recognized.

Such morphosyntactic rules are consciously and creatively employed, in a manner roughly analogous to art, dance, or music. As Hale (1998: 204) has put it:

Some forms of verbal art-verse, song, or chant-depend crucially on morphological and phonological, even syntactic, properties of the language in which [they are] formed. In such cases, the art could not exist without the language, literally.

Burridge and Allan (1998) discuss 'secret languages' (such as 'Pig Latin', 'Eggy Peggy', and 'Upp-upp'), which involve manipulation or remodelling of a language by means of affixation and/or morphophonological permutation (cf. KirshenblattGimblett 1976). They show that not only can these grammatical devices be used to index and/or verify cultural identity, but they can be used to exclude out-groupers, citing the example of Romani 'camouflaging suffixes' which can modify local languages, making them unintelligible to non-in-group members.

Also relevant here are 'sociosyntax' phenomena such as the syntactic variables which distinguished various Harlem gangs from 'lames' (non-gang-members), including expletive subject $i$ in presentational sentences (It's a policeman in that unmarked car), or auxiliary inversion in embedded questions (He asked me could I go there; Labov 1972, cited in Chambers 1995: 92-3). Wolfram and Fasold (1974: 164) describe grammatical variables in non-standard varieties of English, such as multiple negation (We ain't never had no trouble about none of us pulling out no $k n i f e$ ), and copula deletion (He busy right now). The contribution to this volume by Diller and Khanittanan describes some of the sociocultural correlates with grammatical alternatives in Thai.

\subsubsection{Syntax from the native's perspective}

Cultural institutions may affect grammatical structure through the efforts of grammarians themselves, via the academic culture of linguistic science. Pennycook rightly describes linguistics as 'a very particular cultural form' (Pennycook 1994: 125). Accordingly, grammatical description is constrained by culture-specific assumptions, objectives, expectations, superstitions, and taboos. It is, among other things, an art. Cultural preoccupations of modern grammarians include deference to scientific principles like parsimony of description, logical argumentation, and the aim for neat generalizations; awareness of the special attention paid within the culture to those who publish important counter-examples or unusual data, or make strong and/or controversial claims; career ambition; the tension between a desire 
to follow an original approach, to adopt a fashionable research agenda, or to discover the truth; and so on (cf. Harris 1980, 1987; Murray 1994; Pennycook 1994: $114 \mathrm{ff}$.). And grammatical traditions in radically different cultures may indeed be radically different in form. There is no better demonstration of this than a comparison of the standard modern linguistic grammar with the ancient Sanskrit grammar of Pänini (Katre 1987). Our training in the culture of grammarians has a coercive effect on how we gather and analyse linguistic data, how we write about it, and how we interpret what we read about it. This issue is further explored by Diller and Khanittanan (this volume), the only contributors who take the term "ethnosyntax' to mean 'syntax from the native's point of view' (i.e. analogous to terms like 'ethnopsychology' and 'ethnobiology'). Andy Pawley, also, touches on this issue in an 'afterthought' to his chapter. He argues that traditions of normative grammar can cause grammarians not even to notice some facts about grammatical structures in real language use.

An area of grammarians' practice strongly tied to culture is the notion of 'grammaticality' (and/or 'acceptability'), a problem also explored by Diller and Khanittanan (this volume). Syntacticians traditionally rely on a binary distinction between 'grammatical' and 'ungrammatical' utterances - those which are 'part of the grammar' and those which are not-and yet we are all acquainted with that expansive middle ground in which an adjustment to the 'unmarked' context can make an otherwise 'ungrammatical' utterance perfectly good. Kay (1996: 112) rejects Sybil had John fall off the couch, yet he himself shows that the string is fine in the right context. The causative verb have requires its lower verb to be agentive, but the lower verb fall, rather than entailing non-agentivity, merely implies nonagentivity, since people do not typically fall on purpose. This typification is easily overridden by a licensing (albeit marked) cultural context - theatre-in which people $d o$ fall on purpose. The 'ungrammaticality' of Kay's starred sentence is of a completely different order from, say, that of *Couch John Sybil off had fall the. ${ }^{8}$ My own contribution to this volume discusses a case in which sentences judged by speakers as odd, and even unacceptable, due to 'logical' problems, are later produced spontaneously by the same speakers. It turns out that the 'logic' involved in many grammaticality or acceptability judgements makes reference to what is culturally normal. A culturally atypical scenario can successfully elicit a supposedly 'ungrammatical' structure.

The culture of grammarians can not only affect the way language is described, but this culture-mediated description can also turn around and affect the language itself, via 'self-fulfilling prophecy' effects of prescriptive grammar, often associated with social modernization, nationalism, and the politically motivated official language standardization that inevitably goes with it (Lucy 1996: 59-63; Fish-

${ }^{8}$ Work on 'verb class semantics', such as that in Dowty 1979, Foley and Van Valin 1984, Frawley 1992: ch. 4 and references therein, is a good example of an area in which the culturally normal plays a central role in whether and/or how various combination are interpreted. 
man 1997). Diller $(1988,1993)$ has documented changes that Thai has undergone, resulting directly from language engineering inspired by a combination of influences from Sanskrit and Western grammar, selectively appropriated by authorities with essentially political aims. This has resulted in an expanded classifier system, a more developed system of speech-act particles and various politeness-marking forms, elaborated systems of overt subordination or adjunction (complementizers, 'prepositions'), and reduced deictic and pronominal systems, among other things. A final example of modernization affecting grammar is the global spread of an impersonal sentence type modelled on the English passive construction, usually due to translation of news, instruction manuals, or educational textbooks of foreign origin (Blake 2001).

\subsubsection{Culture, pragmatics, and semantic change}

The 'broad' and 'narrow' senses of ethnosyntax are not exclusive. One important way in which they are linked is in the semanticization (in grammar) of pragmatic inferences based on cultural logic (Wilkins 1991; Enfield 2000a, 2002), one mechanism, perhaps the main one, by which 'narrow' phenomena (i.e. cultural semantics in grammar) emerge out of 'broad' phenomena (i.e. culturally mediated patterns of use or interpretation of grammar). These mechanisms can provide accounts for 'linkage' in psychologically based explanations of why grammar is structured as it is (Clark and Malt 1984; Hall 1992; see s. 1.3 .3 below for discussion). Pragmatic inferences drive the processes of semantic change known as 'grammaticalization', and account for how particular grammatical resources come to exist in the first place (Traugott and Heine 1991; Hopper and Traugott 1993). Semantic change involves, first, a stage where a meaning $p$ of an expression regularly gives rise, via pragmatic inference, to an interpretation $q$, then secondly, a stage where $q$ becomes wholly conventionalized as an alternative meaning of the expression (i.e. the expression becomes polysemous; Evans and Wilkins 2000: 549-50; Enfield 2002: 28-30). Once two separate meanings are conventionalized, they may diverge, and the semantic connection between the new signs may become tenuous (despite their being signified by a single phonological form).

Where culture comes into play in this process is in providing culture-specific premisses driving the pragmatic inferences which eventually harden to become semantically encoded in morphosyntax. It is routinely claimed that pragmatic inferences-such as those behind the metonymic shifts that go and since have undergone in English-are made upon 'general' (i.e. universal, non culture-specific) cognitive principles (e.g. Sweetser 1990). But culture-specific principles can also play a hand (Keesing 1979: 27; Evans and Wilkins 2000: 550, 580-5). Inferential processes are based on premisses found in our cultural currency. As Levinson (1995: 240) has argued, the premisses culture provides may be viewed as heuristics for figuring out the intentions behind others' words and actions. Those who share the same common ground-i.e. the same 'cultural premisses'-will 
naturally make the same kinds of inferences (cf. Hutchins 1980; Levinson 1995; Enfield $2000 a$, this volume).

\subsection{METHODOLOGICAL ISSUES}

The study of grammar and culture confronts a host of thorny methodological and theoretical problems. The investigator must $(a)$ adopt a sound approach to semantic description, $(b)$ adopt a sound approach to cultural description, and $(c)$ have a sound and plausible way of showing the relationship between these. Among existing approaches to the language-culture relationship, there are differing views as to what counts as an adequate demonstration of a putative culture-grammar relationship. I concentrate here on five issues that are most important in the context of this book: the description of grammar, the description of culture, characterizing the linkage between grammar and culture, the question of linguistic relativity, and the risk of circularity in argumentation.

\subsubsection{Describing grammar}

In research on the grammar-culture relationship, one cannot work at the level of overarching generalizations of a language's grammatical 'type'. Rather, one must examine specific morphosyntactic structures and/or resources and make explicit hypotheses as to their meanings. As Wierzbicka notes (1979: 378), 'a formal, rigorous analysis of meanings grammaticalized in different languages is a necessary prerequisite for any systematic study of correlations between linguistic and extralinguistic aspects of culture' (see also Langacker, this volume). The same point is made by Mathiot (1979: pp. ix-x), who says that 'without a better substantive knowledge than we presently have of the meanings communicated through language, any further enquiry into the relation of language to the rest of culture runs the danger of being vacuous' (cited in Wilkins 1993: 91).

To assess the relationship between culture and grammar one's approach to the latter needs especially to ask what a given morphosyntactic resource or construction means. Three approaches which prioritize meaning in the description of grammar are especially relevant in this context. First, 'cognitive grammar' (Langacker $1987,1990,1991)$ gives priority to conceptual and 'imagic' aspects of the grammatical organization of meaning. The approach assigns semantics to grammatical resources in much the same way as it does to lexical items (see Langacker, this volume). ${ }^{9}$ A second approach is 'construction grammar', as originated by Fillmore and

\footnotetext{
${ }^{9}$ Palmer (1996) has recently argued that cognitive linguistics--the broader movement in which Langacker's Cognitive Grammar is situated-'can be applied directly to language and culture' (1996: 4), since the approach 'centres on linguistic imagery, which is largely defined by culture' (1996: 290). Palmer argues that by incorporating recent developments in cognitive linguistics into the continuing development of cognitive anthropology, we can "reconstitut[e] linguistic anthropology as an imagerycentred, cultural theory of language that weaves some bright new cognitive strands into the historical tapestry of our field' (Palmer 1996: 296).
} 
colleagues (Fillmore 1988; Fillmore, Kay, and O’Connor 1988; Goldberg 1995, 1997), which regards the semantics of constructions as essentially equivalent to the semantics of lexical items, given that the semantics of productive constructions can be demonstrated not to be derived or 'projected' from constituent parts, and furthermore that constructions-like words-can be polysemous (Goldberg 1997: 163-5). Third, a semantic approach to grammar developed by Wierzbicka and colleagues maintains that 'there is no fundamental gulf between grammatical semantics and lexical semantics' (Goddard 1998: 320; see Wierzbicka 1988). In the view of these three modern traditions, the central task of grammatical description is to provide explicit definitions of meanings encoded in grammatical structure.

One area of research among more formal approaches to syntax which has actively begun to acknowledge and incorporate a great deal of cultural information into its account is the field of natural language processing. Researchers engaged in the mind-boggling work of trying to get computers to process natural language have long grappled with problems of grammatical (and lexical) ambiguity (cf. Deemter and Peters 1995; Hirst 1987; inter alia). Real speakers can effortlessly disambiguate strings like John had Bill removed from the organization after he figured out what was going on or Moving furniture can hurt your back, by referring to the context and to an enormous catalogue of background knowledge, both 'public' (known to be shared by some general population), and 'private' (known to be shared among given individuals). Much of this 'knowledge base' (Buvač 1995) is nothing other than culture.

To begin asking questions about the relation of grammar and culture, one must at least adopt a view of grammatical constructions as meaningful. While not without its merits, a purely formal approach to grammar can be of little aid to linguistic anthropology (other than to those who study the cultural practices of grammarians; see s. 1.2.1.3 above).

\subsubsection{Describing culture}

Culture has been defined in very many ways, the most important general positions being 'culture is knowledge', 'culture is symbols', and 'culture is action' (see Duranti 1997: ch. 2; Layton 1997 for recent overviews). Despite routine portrayal of the many approaches to cultural description as conflicting alternatives, they are often not fundamentally incompatible at all-it usually boils down to a difference of opinion as to what is interesting. ${ }^{10}$ In turn, within the realm of 'culture', however it is conceived, there are different levels one can focus on in relation to languageone may be interested in widely adopted 'values', in the on-the-ground patterns of inter- and intra-societal organization, or in the abstract structures which underlie

\footnotetext{
${ }^{10}$ This is often linked to preoccupations with sociopolitically distinct 'research agendas' and the cliques that cohere around them and their charismatic and/or politically influential leaders (Murray 1994).
} 
and regulate sociocultural arrangements. What is important is that in adopting a view of some aspect of culture in the context of its relation to grammar, given that the two are both fundamentally semiotic in nature, one needs a way of describing cultural meanings such that they can be coherently related to grammatical meanings. Cultural description is not easy, but I would steadfastly oppose suggestions that linguists 'leave [problems of culture] to the anthropologists' (Trudgill 1997: 358 ), as if linguists cannot, or should not, venture into such ground. To the contrary, linguists are practitioners of anthropology in one of its major forms, and ought to embrace this fact by considering the relevance to their work of the broader range of social and semiotic phenomena.

A significant stumbling block is the issue of 'cultures' (as opposed to 'culture'), and whether it is possible at all to characterize 'a culture', and/or to generalize about its members, their practices, values, and/or beliefs. D'Andrade argues that the idea of a culture as a complex whole is 'an article of faith, since no one ever offered an empirical demonstration of any culture's structure' (1995: 249). Indeed, it is today a matter of routine to eschew the idea that we can speak of 'cultures' at all. Bickel (2000: 164), for example, says that "any notion of "THE culture of $x$ " is highly suspicious if at all viable'. (Cf. Wierzbicka 1997: 17-22, Brown in press for different views.)

The very mention of an overarching object such as 'Australian culture' or 'Russian culture' regularly elicits a shrill response. Interestingly, linguists who feel most strongly about the mere mention of 'this culture' or 'that culture' are often those most ready to defend the discreteness of 'languages' and the legitimacy of making generalizations about their structure. Yet D'Andrade's point about the lack of any empirical demonstration of 'a culture' can be made about 'languages' too. Linguists deal with words and constructions which appear to be part of the common ground, or 'idiolectal intercalibration' (Hockett 1987: 106-7, 157-8) of some (theoretically) definable group, but it remains the case that we never encounter or describe a thing we may call 'the language'. We successfully proceed with linguistic description as if we were describing aspects of a coherent whole. It is possible - with care- to similarly proceed with cultural description.

Generalizations along the lines of 'egalitarianism is important and/or significant in Anglo Australian culture' are common, and are often taken to imply reference to some coherent whole 'Anglo Australian culture'. But there is no necessary connection between a claim that a particular cultural idea has currency across a large definable group, and a conclusion that this must be the tip of a monolithic iceberg we will call 'the culture'. A 'monolithic' view and a 'generalization' view are logically distinct. Assuming that exhaustive characterization of 'a culture' that is real and/or relevant for all individuals who identify and/or are identified as members is not possible, let us instead consider what a cultural 'generalization' might amount to.

Claims such as 'egalitarianism is part of Anglo Australian culture' can be interpreted in a number of ways. For example: 
(a) Egalitarianism exists in Anglo Australian society.

(b) Anglo Australians hold egalitarian values (regardless of the truth of $(a)$ ).

(c) A certain community of people may be defined by their knowledge that there may be assumed, among (Anglo) Australians, a popular belief that egalitarian values are widely held by (Anglo) Australians (regardless of the truth of $(a-b)$ ).

Making generalizations about 'cultures' is highly problematic if the claim is that 'the culture' itself is empirically definable, in an extensional sense, and that the description is of some structure 'in the world'. Neither $(a)$ nor $(b)$ is viable. However, it is possible to approach cultural generalizations as descriptions of ideas about social identities, and about what is collectively assumed to be 'normal'-or, more precisely, what is assumed to be assumed to be normal (as in (c)). Crucially, the sense of 'normal' here can be at some remove from what actually is normal (however that is defined). Accordingly, Green treats 'normal belief' as a technical term, defined as follows: 'If everybody believes that everybody believes that it is normal to believe $P$, then belief in $P$ is a normal belief, EVEN IF NOBODY ACTUALLY BELIEVES P' (Green 1995: 13, original emphasis). It is the stereotype ideas themselves, mythical or not, that are important in accounting for cultural logic, and emotional disagreements over whether it is valid to generalize about human groups or 'cultures' usually arise out of confusion as to whether the generalization intended is extensional (hardly tenable) or intensional (more like it; cf. Green 1995: 13)-i.e. whether the stereotype claims to describe the facts or whether it claims to describe some context-based default premisses for cultural logic, which must be known about, but not necessarily committed to (cf. also Putnam 1975: $249 \mathrm{ff}$.).

The idea is akin to the 'maxims' which guide our interpretations of linguistic utterances in context (Grice 1975). A maxim such as 'avoid obscurity' is not a rule to be obeyed - we grapple daily with the obscurity (intentional or not) of our social associates. Rather, it is a working assumption for interpreting others' actions (and with respect to which one knows that one's own actions will be interpreted). And when the facts run against this assumption, it is the very presence of the assumption which makes the marked scenario marked. Cultural stereotypes work in exactly the same way.

Apart from the issue of stereotypes, there remains the problem of 'heteroglossia' (Bakhtin 1981: 262-3, 288-300) and analogous variation in culture. No two people's common ground, linguistic and/or otherwise, overlaps perfectly with the common ground of any other two. While members of communities do show many commonalities, there are further levels of commonality and structured relations, both 'nested' within distinct communities (Clark 1996), and extending between culturally quite distinct communities (Leach 1964). In any social setting, individuals maintain multiple identifications, and master, passively and/or actively, multiple linguistic and cultural systems. This is not a reason to abandon cultural description, but it does mean that care must be taken (Enfield 2000a: 54-7). 


\subsubsection{Linkage}

Scholars concerned with the problem of explaining grammatical structure have pointed to the theoretical and methodological need not merely to identify correlations (e.g. between a putative psychological or cultural constraint and a grammatical construction of a certain kind), but also to offer plausible causal mechanisms by which observed correlations can be supported. In their discussion of possible 'psychological constraints on language', Clark and Malt (1984) offer four ideal properties that any proposed constraint should possess- 'empirical grounding', 'structure independence', 'theoretical coherence', and 'linkage', the latter being 'probably the most challenging' (Clark and Malt 1984: 201). They note (1984: 198) that most commonly an account of the linkage between a 'psychological process' and a structured feature of language will involve mechanisms of linguistic change, or linguistic creation (i.e. of pidgins and creoles). Accordingly, historical processes provide the strongest support of linkage between descriptively correlated grammatical and cultural facts, as reported in the contributions to this volume by Burridge and Simpson. Section 1.2.2 above discussed the process whereby morphosyntactic constructions and categories can emerge out of the use of cultural assumptions as premisses in the pragmatic inferential processes which drive semantic change.

In his discussion of what constitutes 'explanation' in linguistics, Hall (1992: 37) says that psycholinguistics is 'indispensable'. In the present context, this is correct in as far as cultural and social facts can be reduced to psychological facts (which I think they probably can, cf. Enfield 2000a). Some important concepts in psycholinguistics-including 'common ground' (Clark 1996: $332 \mathrm{ff}$.), 'heuristic strategies' (Clark and Malt 1984: 203), 'scripts' and 'schemas' (Mandler 1984), 'context' (Buvač 1995; Green 1995)-in fact are squarely matters of culture, but they are usually described with terms like 'local knowledge', 'prototypes', 'stereotypicality', even 'common sense'. Indeed, psycholinguistics in its current form expresses little interest in ethnography. But the kind of material presented in this book shows that psycholinguistics can broaden the scope of what counts as "psychological' (this obviously includes the subject matter of 'psychological anthropology' and 'cultural psychology'; Shweder and LeVine 1984; Holland and Quinn 1987; Stigler, Shweder, and Herdt 1990; Schwartz, White, and Lutz 1992; Strauss and Quinn 1997; inter alia).

\subsubsection{Linguistic relativity}

The term 'linguistic relativity' refers to that famous principle developed by scholars such as Humboldt, Sapir, and Whorf, which asserts, for example, that '[c]oncepts of "time" and "matter" are not given in substantially the same form by experience to all men but depend upon the nature of the language or languages through the use of which they have been developed' (Whorf 1956: 158). An important point about Whorf's idea of linguistic relativity is that the 'influence' of language on thought 
was not viewed as a function of isolated, or indeed isolable aspects of a linguistic system, but associated with 'the ways of analysing and reporting experience which have become fixed in the language as integrated "fashions of speaking" and which cut across the typical grammatical classifications' (Whorf 1956: 158). By some, this principle has been taken to be a 'hypothesis', testable via isolation of linguistic facts on the one hand, and non-linguistic facts on the other, followed by empirical demonstration of a correlation between the two (Lucy 1992a, 1992b). Others have regarded this 'hypothesis' view as a misconstrual of what was originally intended, namely a principle (Hill and Mannheim 1992; Lee 1996, 2000). Lee (1996: 78) points out that the 'deliberate operational separation of language and thought in order to accommodate theoretical preconditions for empirical investigation' erroneously presupposes that this separation is possible at all. While Lee mentions only 'thought' here, it is clear that her comments are meant to apply also to 'culture'. For Hill and Mannheim (1992: 382), similarly, the 'separation of "language" and "nonlanguage" such that these can be then "related" one to another' is problematic. As far as they are concerned, the "notion of the "linguistic" versus the "nonlinguistic" eludes contemporary cultural anthropologists' (cf. Enfield 2000b). This has obvious methodological consequences for ethnosyntax. ${ }^{11}$

While the principle of linguistic relativity is of course relevant to our present concerns, the study of ethnosyntax need not be specifically concerned with comparing languages and seeing how the differences may relate to corresponding cultural differences. 'Cultural' does not entail 'culture-specific'- that is, as long as you believe in some cultural universals. But this of course does not mean that ethnosyntax should not be a comparative enterprise. Studies in ethnosyntax can and should be comparative, as Lucy $(1992 a, 1996)$ has recently emphasized. (See contributions to this volume by Wierzbicka, Newman, and Langacker.) Explicit comparison between particular languages and cultures is obviously a most effective method, especially where they differ in minor, but specific ways, throwing the more subtle linguistic and/or cultural differences into sharper relief.

However, it may not necessarily be the primary aim of a particular study in ethnosyntax to address linguistic diversity per se. If solid argumentation based on extensive linguistic and ethnographic data can be used to establish a connection between cultural and grammatical facts, this is not intrinsically weakened by the lack of comparative contrast with another language and culture (pace Lucy 1992a). Nothing entails that a given cultural preoccupation will show some manifestation in grammar. For one thing, certain grammatical developments in languages may be licensed or constrained by different existing typological profiles (cf. Aikhenvald and Dixon 1998: 254; Enfield 2001: 284-7). Conversely, if a similar morphosyntactic feature is attested among unrelated speech communities, to what extent can we

\footnotetext{
1 Unfortunately, the two sides to this debate, typified by Lee on one hand, and Lucy on the other, are often wrongly treated as competing or even conflicting alternatives. In many respects they are not in conflict, and indeed the achievements of each approach complement those of the other.
} 
expect these groups to share some associated cultural preoccupation? Most would agree that the answer is 'not necessarily at all', as John Newman shows in his contribution to this volume, referring to a morphosyntactic parallel between Nahuatl and Zulu which has no obvious corresponding cultural parallel. But this is not a simple problem. First, as Lee (1996) has stressed, such grammatical/behavioural phenomena need to be examined not in isolation, but as elements of large-scale fashions of speaking (Whorf 1956). Second, it is not necessarily the case that the existence of a given grammatical feature will have a cultural explanation anyway. Third, the same grammatical feature in two languages could logically be the outcome of processes relating to different cultural phenomena. (For further discussion of these points, see the contributions to this volume by Chafe, Newman, and Pawley.)

Another reason that an ethnosyntax claim is not necessarily a relativist claim is that - theoretically - a relationship between particular cultural and grammatical phenomena might well apply universally. After all, most would expect there to be universals in both language and culture. Consider the morphosyntactic effects of the substantival hierarchy (i.e. the hierarchy of accessibility of different nominal types, such as pronouns versus full noun phrases, to certain grammatical phenomena such as ergative case-marking; Silverstein 1976), where indeed it appears that a universal pattern in conceptualization (i.e. the relative focus of interest and attention on the members of the interaction dyad, other people, animates, inanimates, and so on) gives rise to a system with some morphosyntactic effect in most if not all languages. ${ }^{12}$ Can we interpret a conceptual schema like the substantival hierarchy as cultural? The same could be asked of many other universal functions of grammar, such as the global need to distinguish semantic roles in asymmetrical transitive expressions. The particular method of making this functional distinction in a given language (e.g. by case-marking, cross-referencing, and/or constituent order) is certainly common ground among speakers in the given speech community, and so therefore may (trivially?) be regarded as 'cultural'. Consider John Newman's note (this volume) that while there is great variation in the way languages model the syntax of 'give' expressions on the grammar of prototypical transitive expressions, apparently none treat the 'giver' argument morphosyntactically as a direct object. Is this due to a general, cognitive constraint, a universal cultural one, or somehow both?

\subsubsection{Characterization of the language-culture connection: circularity?}

Finally, we may consider more closely a point touched upon early in the previous section, regarding the distinction between a 'hypothesis' approach to the language-culture relationship (in which a putative correlation between operationally distinct phenomena is tested experimentally) and a 'principle' approach (which

\footnotetext{
12 See papers in Goody (1995) for explorations of the thesis that human intelligence is fundamentally oriented towards dyadic interaction.
} 
aims to characterize the relationship between language and culture based on an initial assumption of their fundamentally inseparable nature). If one takes the first view (cf. Lucy 1992a, 1992b, 1996), then there emerges the danger of a certain kind of circular argumentation. Indeed, one of Lucy's most emphatic points is the methodological need for studies in linguistic relativity to avoid this. In trying to separately describe facts about morphosyntactic resources available to speakers, as distinct from facts of a cultural nature about those speakers, and relate these two together, it is naturally unacceptable to adopt genuinely circular argumentation. One could not use a linguistic feature as evidence for some cultural feature and then claim that this cultural feature correlates with the linguistic feature, thus 'establishing' a culture-grammar link. A connection between culture and language would have been assumed in the first place, since the linguistic feature was admitted as evidence for the cultural feature. Yet the connection in question was what the analysis was supposed to demonstrate. Hale also wants to avoid this, arguing that 'establishing a connection or relation between a philosophical postulate and a principle of grammar requires that the two be established independently' (Hale 1986: 233). So, two options are (a) to avoid the 'linguocentrism' of the argument by using only non-linguistic evidence to establish claims about culture-what we may call the 'non-linguistic evidence' position- or $(b)$ to assume from the outset a principle of language-culture relatedness, and explore its various manifestations, rather than try to 'prove' it-what we may call the 'fashions of speaking' position.

If claimed to be the only way to explore the culture-grammar relationship, the 'non-linguistic evidence' position goes too far. Logically, in order to avoid the circularity described above, it is necessary that the evidence for establishing a cultural fact be independent of the relevant linguistic phenomena, but not necessarily non-linguistic. In other words, it need not be independent of language as a whole, but rather of the particular linguistic phenomenon under discussion. ${ }^{13}$ One consequence of a decision to rule out any use of linguistic evidence in cultural description would be a seriously impoverished ethnography. Lucy of course recognizes that to reject linguocentrism 'is not to say that vocabulary items do not reflect nonlinguistic culture or that discourse using language does not provide important evidence about cultural beliefs', but he suggests that 'from a methodological point of view, such materials cannot be persuasive by themselves in showing the broader effects of language' (Lucy 1996: 44). Thus, his objection is apparently not to linguocentrism per se, but simply to logical circularity, which may easily result from simple-minded argumentation involving linguistic evidence not independent of the phenomena being examined (cf. Enfield $2000 \mathrm{~b}$ for further discussion).

From a 'fashions of speaking' position, the mere fact of using linguistic evidence in cultural description does not entail circularity. While just one piece of

\footnotetext{
${ }^{13}$ Clark and Malt (1986: 207) point out that facts about linguistic use can be considered independent of facts about linguistic structure (with respect to the proposed methodological requirement of 'structure independence').
} 
linguistic evidence is naturally not convincing in making a claim about culture, it is possible to provide a wide variety of evidence from many areas of linguistic structure, including lexicon, morphosyntax, idiom, socialization routines, mechanisms of discourse and conversation, linguistic ideologies, and so on. If wide-ranging evidence from a number of such sources points towards a consistent conclusion, then linguistic evidence $c a n$ be convincing in establishing generalizations about culture, without entailing circularity of an argument for language-culture relatedness. Hale (1986) argues that 'world view' (in one of his two senses; cf. s. 1.1, above) is observable in the semantic categories of language, namely in those cases where a 'theme' emerges throughout the language, and, specifically, where examples are found 'in parts of the grammar not otherwise intimately related' (Hale 1986: 238). This sense of 'world view' 'consists in the analysis [by speakers, NJE] of phenomena which is embodied in the system of lexico-semantic themes and semantic categories which function in any grammar (though in different ways and to different extents in distinct languages)' (1986: 237-8). This openly linguocentric position is entirely compatible with Whorf's (1956) notion of fashions of speaking (cf. Hasan 1984; Rumsey 1990; Lee 1996). Wilkins takes the same perspective, arguing with regard to the establishment of cultural meanings from the analysis of grammatical semantics that 'once tells us nothing, twice could be a coincidence, but three times starts to confirm a pattern of regularity' (Wilkins 1993: 84). Thus, linguistic evidence of cultural concerns becomes increasingly convincing as evidence from various areas of a language accumulates. What is crucial is sound semantic description and sound ethnography. This view acknowledges an inherent interconnectedness between language and culture, and sees the point of the exercise as an attempt to describe the ways in which this is manifest. The task of then establishing 'external' connections can test and provide further support to the grammar-culture correlations described.

\subsection{OVERVIEW}

This book is divided into three parts. The first part concerns theoretical and methodological questions of the scope of ethnosyntax (as both a set of phenomena and a field of research). Part II focuses on the cultural significance of grammatical semantics, while Part III is concerned with culture-mediated patterns of use of grammatical resources, and their diachronic effects. The twelve contributions cross-cut and overlap in many ways, and a different organization for the volume could have been just as appropriate. Each of the chapters includes detailed discussion of linguistic and ethnographic data, with a broad cross-linguistic and cross-cultural coverage, and each chapter engages with theoretical and methodological issues.

Languages discussed in detail in this book represent a range of linguistic types from around the world. These include Papuan languages Ku Waru (Rumsey) and Amele (Newman), Australian languages Warumungu and Warlpiri (Simpson), Indo-European languages German (Wierzbicka), Russian (Goddard, Wierzbicka), 
varieties of English (Pawley, Wierzbicka), Pennsylvania German (Burridge), the Austronesian language Maori (Newman), Tai languages Lao (Enfield) and Thai (Diller and Khanittanan), Native American languages Koasati, Nahuatl, and Chipewyan (Newman), Mixtec (Langacker), and the Northern Iroquoian group (Chafe), as well as Japanese and Zulu (Newman). The grammatical phenomena investigated also cover broad ground, including person and pronominal systems (Chafe, Newman, Pawley, Rumsey), modal and directional auxiliaries (Burridge, Simpson), locative constructions (Langacker), causative constructions (Wierzbicka), 'serial verb' structures (Enfield), features of 'give' expressions (Newman), existential and positional constructions (Rumsey), control and other properties of complementation (Diller and Khanittanan, Goddard).

Thematically, most contributions are not restricted to one or other of the socalled 'broad' or 'narrow' senses of ethnosyntax, although some are concerned to directly address this distinction (Rumsey, Goddard, Simpson). Several contributions pay particular attention to the historical dimension of culture-grammar relatedness (Burridge, Chafe, Simpson, Wierzbicka). Simpson, in particular, is concerned to address the methodological importance of historical data in establishing a culture-grammar link. Some contributions emphasize the role of sound semantic description (Langacker, Wierzbicka), while others concentrate on the socially situated usage and productivity of grammatical devices (Enfield, Rumsey). A number of contributions focus on questions of how culture is best described (Enfield, Goddard, Simpson, Wierzbicka). For Burridge and Chafe, available ethnographic data are relied upon to support statements about culture with relevance to the linguistic analyses provided. The theoretical scope of the volume is uniquely enriched by Goddard's contribution, which asks how Peircean semiotic distinctions found in different aspects of grammar are relevant to the characterization of a culture-grammar relationship. His efforts are valuable in a field vexed by confusion (or entire absence) of basic distinctions between different semiotic functions. A final angle which most contributions take is to offer cross-linguistic comparison as a means for focusing the research question (see in particular Chafe, Goddard, Langacker, Rumsey, Simpson, and Wierzbicka). Newman's approach is particularly illustrative of the merits of cross-linguistic comparison, drawing from his long-standing interest in the cross-linguistic structuring of an essentially stable semantic domain, namely 'giving'. This turns out to be a productive focus for cross-linguistic work.

\subsection{CONCLUDING REMARKS}

The scholar who claims to have demonstrated a causal or non-arbitrary link between linguistic and non-linguistic phenomena is prone to criticism. Clark and Malt (1984) outline a set of stringent methodological requirements, arguing that few if any claims to have 'explained' linguistic structure with reference to psychological constraints constitute 'strong arguments' according to their ideals. Even so, 
they argue, exploratory attempts at explanation can be extremely valuable, in that they suggest places to look further for the ideal 'strong arguments'. Such exploratory attempts 'may have their most important value as provocateurs: they goad us to look for strong psychological rationales for universal features of language' (Clark and Malt 1984: 211). Contributors to this book on the one hand show caution (see especially Langacker, Pawley, Simpson). Langacker warns that apparent grammatical differences between two languages, which we may want to associate with cultural differences between speakers of those languages, 'may be less profound and less extensive than they might seem to be on first examination'. Newman similarly argues that while there are grammatical devices whose meaning/function would seem to be culture-specific, there are also cases where no such claim could be made. On the other hand, the very premiss of this book is that it is well worth exploring the idea that a language's morphosyntactic resources are related to the cultural knowledge, attitudes, and practices of its speakers. The results make ethnosyntax a rich and rewarding field of study. If 'strong psychological rationales' are what will explain universal features of language, then may this book encourage interested scholars to seek strong cultural rationales for the subtle (and not so subtle) ways in which languages differ.

\section{REFERENCES}

Aikhenvald, AlEXandra Y., and Dixon, R. M. W. 1998. 'Evidentials and areal typology: a case study from Amazonia'. Language Sciences, 20.3: 241-57.

Alsina, Alex, Bresnan, Joan, and Sells, Peter (eds.). 1997. Complex Predicates. Palo Alto, Calif.: Stanford University Centre for the Study of Language and Information.

Bakhtin, Mikhall M. 1981. The Dialogic Imagination. Austin: University of Texas Press.

BiCKEL, BaLTHAZAR. 2000. 'Grammar and social practice: on the role of culture in linguistic relativity'. In Niemeier and Dirven 2000, 161-92.

BLAKE, BARRY. 2001. 'Global trends in language'. Linguistics, 39.5: 1009-28.

Blount, Ben G. (ed.) 1974. Language, Culture and Society. Cambridge, Mass.: Winthrop.

BoAs, Franz. 1911. 'Introduction'. In Franz Boas (ed.), Handbook of American Indian Languages. Lincoln: University of Nebraska Press, 1-79.

Brown, Penelope. In press. 'Language as a model for culture: lessons from the cognitive sciences'. In R. Fox and B. King (eds.), Anthropology beyond Culture. Berg.

BRUCE, LES. 1988. 'Serialization: from syntax to lexicon'. Studies in Language, 12.1: $19-49$.

Burridge, Kate, and Allan, Keith. 1998. 'The X-phemistic value of Romani in nonstandard speech'. In Y. Matras (ed.), The Romani Element in Non-Standard Speech. Sondersprachenforschung 4. Wiesbaden: Harrassowitz, 29-50.

BUVAČ, SAŠA. 1995. 'Resolving lexical ambiguity using a formal theory of context'. In van Deemter and Peters 1995: 101-24.

Chambers, J. K. 1995. Sociolinguistic Theory. Oxford: Blackwell.

Clark, Herbert H. 1996. 'Communities, commonalities, and communication'. In Gumperz and Levinson 1996: 324-55. 
-and MALT, Barbara C. 1984. 'Psychological constraints on language: a commentary on Bresnan and Kaplan and on Givón'. In Walter Kintsch, James R. Miller, and Peter G. Polson (eds.), Methods and Tactics in Cognitive Science. Hillsdale, NJ: Lawrence Erlbaum, 191-214.

Craig, Colette Grinevald. 1986. 'Jacaltec noun classifiers: a study in language and culture'. In Colette Craig (ed.), Noun Classes and Categorization. Amsterdam: John Benjamins, 263-93.

D'ANDRADE, Roy. 1995. The Development of Cognitive Anthropology. Cambridge: Cambridge University Press.

DeEmter, Kees van, and Peters, Stanley. 1995. Semantic Ambiguity and Underspecifcation. Stanford, Calif.: CSLI Publications.

DENCH, ALAN. 1987. 'Kinship and collective activity in the Ngayarda languages of Western Australia'. Language in Society, 16: 321-40.

Diffloth, G. 1979. 'Expressive phonology and prosaic phonology in Mon-Khmer'. In Theraphan L. Thongkhametal. (eds.), Studies in Mon-KhmerPhonetics and Phonology in Honour of Eugenie J. A. Henderson. Bangkok: Chulalongkorn University Press, 49-59.

Diller, ANTHONY. 1988. 'Thai syntax and "national grammar"'. Language Sciences, 10.2: $273-312$.

-1993. 'Diglossic grammaticality in Thai'. In William A. Foley (ed.), The Role of Theory in Language Description. Berlin: Mouton de Gruyter, 393-420.

Dixon, R. M. W. 1971. 'A method of semantic description'. In Danny D. Steinberg and Leon A. Jakobovits (eds.), Semantics: An Interdisciplinary Reader in Philosophy, Linguistics, and Psychology. Cambridge: Cambridge University Press, 436-71.

DowTY, DAVID R. 1979. Word Meaning and Montague Grammar. Dordrecht: Kluwer.

DunN, Michael. 2000. 'Chukchi women's language: a historical-comparative perspective'. Anthropological Linguistics, 42.3: 305-28.

Duranti, Allesandro. 1990. 'Politics and grammar: agency in Samoan political discourse'. American Ethnologist, 17.4: 646-66.

-1997. Linguistic Anthropology. Cambridge: Cambridge University Press.

DURIE, MARK. 1997. 'Grammatical structures in verb serialization'. In Alsina, Bresnan, and Sells 1997: 289-354.

ENFIELD, N. J. 2000a. 'The theory of cultural logic: how individuals combine social intelligence with semiotics to create and maintain cultural meaning'. Cultural Dynamics, 12.1: 35-64.

-2000b. 'On linguocentrism'. In Pütz and Verspoor 2000: 125-57.

-2001. 'On genetic and areal linguistics in Mainland Southeast Asia: parallel polyfunctionality of "acquire"'. In Alexandra Aikhenvald and R. M. W. Dixon (eds.), Areal Diffusion and Genetic Inheritance. Oxford: Oxford University Press, 255-90.

-2002. Linguistic Epidemiology: Semantics and Grammar of Language Contact in Mainland Southeast Asia. London: Routledge.

Evans, Nicholas D. 1997. 'Sign metonymies and the problem of flora-fauna polysemy in Australian linguistics'. In Darrell Tryon and Michael Walsh (eds.), Boundary Rider. Canberra: Pacific Linguistics, 133-53.

—and Wilkins, David P. 2000. 'In the mind's ear: the semantic extensions of perception verbs in Australian languages'. Language, 76.3: 546-92.

Ferguson, Charles A. 1964. 'Diglossia'. In Hymes 1964: 429-39 (first pub. Word 15 (1959), 325-40). 
Fillmore, Charles J. 1988. 'The mechanisms of "construction grammar"'. Berkeley Linguistics Society, Proceedings of the 14th Meeting. Berkeley: Berkeley Linguistics Society, 35-55.

- Kay, Paul, and O'Connor, Mary Catherine. 1988. 'Regularity and idiomaticity in grammatical constructions: the case of let alone'. Language, 64.3: 501-38.

Fishman, Joshua A. 1997. In Praise of the Beloved Language: A Comparative View of Positive Ethnolinguistic Consciousness. Berlin: Mouton de Gruyter.

FOLEY, WILliam A. 1997. Anthropological Linguistics. London: Blackwell.

—and VAN VAlin, RoBert D. 1984. Functional Syntax and Universal Grammar. Cambridge: Cambridge University Press.

Frawley, William. 1992. Linguistic Semantics. Hillsdale, NJ: Lawrence Erlbaum.

Goddard, ClifF, 1998. Semantic Analysis: A Practical Introduction. New York: Oxford University Press.

- In press. 'Whorf meets Wierzbicka: variation and universals in language and thinking'. Language Sciences.

Goldperg, Adele E. 1995. Constructions: A Construction Grammar Approach to Argument Structure. Chicago: University of Chicago Press.

-1997. 'Making one's way through the data'. In Alsina, Bresnan, and Sells 1997: 151-73.

Goody, Esther N. (ed.) 1995. Social Intelligence and Interaction. Cambridge: Cambridge University Press.

GRACE, GEORGE. 1987. The Linguistic Construction of Reality. London: Croom Helm.

GREeN, Georgia M. 1995. 'Ambiguity resolution and discourse interpretation'. In van Deemter and Peters 1995: 1-26.

Grice, H. PaUl. 1975. 'Logic and conversation'. In Peter Cole and Jerry L. Morgan (eds.), Speech Acts. New York: Academic Press, 41-58.

GuMPERz, JoHN L., and LEVINSON, STEPHEN (eds.). 1996. Rethinking Linguistic Relativity. Cambridge: Cambridge University Press.

- and WILSON, RoBerT. 1971. 'Convergence and creolization: a case from the IndoAryan/Dravidian border in India'. In Dell Hymes (ed.), Pidginization and Creolization of Languages, 151-67. Cambridge: Cambridge University Press.

HALE, KenNeth L. 1966. 'Kinship reflections in syntax: some Australian languages'. Word, 22: 318-24.

-1986. 'Notes on world view and semantic categories: some Warlpiri examples'. In Pieter Muysken and Henk van Riemsdijk (eds.), Features and Projections. Dordrecht: Foris, 233-54.

1998. 'On endangered languages and the importance of linguistic diversity'. In Lenore A. Grenoble and Lindsay J. Whaley (eds.), Endangered Languages. Cambridge: Cambridge University Press, 192-216.

Hall, Christopher J. 1992. Morphology and Mind: A Unified Approach to Explanation in Linguistics. London: Routledge.

HARRIS, ROY. 1980. The Language-Makers. Ithaca, NY: Cornell University Press.

1987. The Language Machine. London: Duckworth.

HASAN, RuQAIYa. 1984. 'What kind of a resource is language?' The Australian Review of Applied Linguistics, 7.1: 57-85.

Heath, JefFrey, Merlan, FrancesCa, and Rumsey, Alan (eds.) 1982. The Languages of Kinship in Aboriginal Australia. Sydney: University of Sydney Press. 
HerCus, LuISE, and White, IsoBel. 1973. 'Perception of kinship structure reflected in Adnjamathanha pronouns'. Papers in Australian Linguistics, 6. Canberra: Pacific Linguistics, 47-72.

HiLl, JANE H. 1969. 'Volitional and non-volitional verbs in Cupeño'. Papers from the Regional Meeting of the Chicago Linguistic Society, 5: 348-56.

— and MANNHEIM, BRUCE. 1992. 'Language and world view'. Annual Review of Anthropology, 21: 381-406.

HIRST, GRAeme. 1987. Semantic Interpretation and the Resolution of Ambiguity. Cambridge: Cambridge University Press.

HOCKETT, CHARLES F. 1987. Refurbishing our Foundations: Elementary Linguistics from an Advanced Point of View. Amsterdam: John Benjamins.

HoIJER, HARRY. 1953. 'The relation of language to culture'. In A. L. Kroeber (ed.), Anthropology Today. Chicago: University of Chicago Press, 554-73.

-1964. 'Cultural implications of some Navaho linguistic categories'. In Hymes 1964: $142-48$.

Holland, DoROThy, and QuinN, NAOMI (eds.). 1987. Cultural Models in Language and Thought. Cambridge: Cambridge University Press.

Hopper, Paul J., and Traugott, Elizabeth Closs. 1993. Grammaticalization. Cambridge: Cambridge University Press.

Hutchins, Edwin. 1980. Culture and Inference: A Trobriand Case Study. Cambridge, Mass.: Harvard University Press.

Hymes, DeLl H. 1961. 'On typology of cognitive styles in language (with examples from Chinookan)' . Anthropological Linguistics, 3.1: 22-54.

-_ed.) 1964. Language in Culture and Society: A Reader in Linguistics and Anthropology. New York: Harper \& Row.

-1966. 'Two types of linguistic relativity (with examples from Amerindian ethnography)'. In William Bright (ed.), Sociolinguistics. Proceedings of the UCLA Sociolinguistics Conference. The Hague: Mouton, 114-67.

Katre, Sumitra M. 1987. Aștāanhyāyi of Pānini. Austin: University of Texas Press.

KAY, PAUL. 1996. 'Intra-speaker relativity'. In Gumperz and Levinson 1996: 97-114.

KeEsing, Roger M. 1979. 'Linguistic knowledge and cultural knowledge: some doubts and speculations'. American Anthropologist, 81: 14-36.

Kirshenblatt-Gimblett, B. (ed.) 1976. Speech Play. Philadelphia: University of Pennsylvania Press.

LABov, WiLliam. 1972. Language in the Inner City: Studies in the Black English Vernacular. Philadelphia: University of Pennsylvania Press.

LAKOFF, GEORGE. 1986. 'Frame semantic control of the coordinate structure constraint'. In A. M. Farrell et al. (eds.), Papers from the Parasession on Pragmatics and Grammatical Theory. Chicago: Chicago Linguistic Society, 152-67.

-1987. Women, Fire, and Dangerous Things: What Categories Reveal About the Mind. Chicago: University of Chicago Press.

LANDAR, Herbert. 1966. Language and Culture. New York: Oxford University Press.

Langacker, Ronald W. 1987. Foundations of Cognitive Grammar, i: Theoretical Prerequisites. Stanford, Calif.: Stanford University Press.

1990. Concept, Image, and Symbol: The Cognitive Basis of Grammar. Berlin: Mouton de Gruyter.

-1991. Foundations of Cognitive Grammar, ii: Descriptive Applications. Stanford, Calif.: Stanford University Press. 
Langacker, Ronald W. 1994. 'Culture, cognition, and grammar'. In Martin Pütz (ed.), Language Contact and Language Conflict. Amsterdam: John Benjamins, 25-53.

LaYTon, RoBert. 1997. An Introduction to Theory in Anthropology. Cambridge: Cambridge University Press.

LeaCh, Edmund. 1964. Political Systems of Highland Burma. London: The Athlone Press (first pub. 1954).

LeE, DoROThy D. 1959. 'Linguistic reflection of Wintu thought'. In Dorothy D. Lee (ed.), Freedom and Culture. Englewood Cliffs, NJ: Prentice-Hall, 21-30.

Lee, Penny. 1996. The Whorf Theory Complex: A Critical Reconstruction. Amsterdam: Benjamins.

-2000. 'When is "Linguistic Relativity" Whorf's Linguistic Relativity?' In Pütz and Verspoor 2000: 45-68.

LEVINSON, STEPHEN C. 1995. 'Interactional biases in human thinking'. In Goody 1995: $221-60$.

2000. Presumptive Meanings: The Theory of Generalized Conversational Implicature. Cambridge, Mass.: MIT Press.

LuCY, John. 1992a. Language Diversity and Thought: A Reformulation of the Linguistic Relativity Hypothesis. Cambridge: Cambridge University Press.

_ 1992b. Grammatical Categories and Cognition: A Case Study of The Linguistic Relativity Hypothesis. Cambridge: Cambridge University Press.

— 1996. 'The scope of linguistic relativity'. In Gumperz and Levinson 1996: 37-69.

Mandler, JeAn MatTer. 1984. Stories, Scripts, and Scenes: Aspects of Schema Theory. Hillsdale, NJ: Lawrence Erlbaum.

Mathiot, Madeleine. 1964. 'Noun classes and folk taxonomy in Papago'. In Hymes 1964: 154-61.

- (ed.) 1979. Ethnolinguistics: Boas, Sapir and Whorf Revisited. The Hague: Mouton.

Mithun, MarianNe. 1984. 'The evolution of noun incorporation'. Language, 60.4: 847-94.

MurRAY, StePhen O. 1994. Theory Groups and the Study of Language in North America: A Social History. Amsterdam: John Benjamins.

Newman, John. 1996. Give: A Cognitive Linguistic Study. Berlin: Mouton de Gruyter.

NiEmeIER, S., and DiRven, R. (eds.) 2000. Evidence for Linguistic Relativity. Amsterdam: John Benjamins.

O'Grady, GEofF. 1960. 'Comments on "More on lexicostatistics"'. Current Anthropology, $1 ; 338-9$.

Palmer, Gary B. 1996. Toward a Theory of Cultural Linguistics. Austin: University of Texas Press.

PennyCOOK, Alastair. 1994. The Cultural Politics of English as an International Language, London: Longman.

Prideaux, Gary D. 1970. The Syntax of Japanese Honorifics. The Hague: Mouton.

Putnam, Hilary. 1975. Mind, Language, and Reality: Philosophical Papers, vol. ii. Cambridge: Cambridge University Press.

Pütz, MARTIN, and VerSPOOR, MARJOLIN (eds.). 2000. Explorations in Linguistic Relativity. Amsterdam: John Benjamins.

RICE, SALLY. 1998. 'Giving and taking in Chipewyan: the semantics of THING-marking classificatory verbs'. In John Newman (ed.), The Linguistics of Giving. Amsterdam: Benjamins, 97-134. 
RUMSEY, AlaN. 1990. 'Wording, meaning, and linguistic ideology'. American Anthropologist, 92: 346-61.

Rushforth, Scott, and Chisholm, James S. 1991. Cultural Persistence: Continuity in Meaning and Moral Responsibility among the Bearlake Athapaskans. Tucson: University of Arizona Press.

SAPIR, EDWARD. 1949. Selected Writings. Berkeley and Los Angeles: University of California Press.

1994. The Psychology of Culture, reconstructed and ed. by Judith T. Irvine. Berlin: Mouton de Gruyter.

SChUtz, Alfred. 1970. On Phenomenology and Social Relations. Chicago: University of Chicago Press.

Schwartz, Theodore, White, Geoffrey M., and Lutz, Catherine A. (eds.) 1992. New Directions in Psychological Anthropology. Cambridge: Cambridge University Press.

Shibatani, MaSayoshi. 1990. The Languages of Japan. Cambridge: Cambridge University Press.

Shweder, Richard A., and LeVine, Robert A. (eds.). 1984. Culture Theory: Essays on Mind, Self, and Emotion. Cambridge: Cambridge University Press.

Silverstein, Michael. 1976. 'Hierarchy of features and ergativity'. In R. M. W. Dixon (ed.), Grammatical Categories in Australian Languages. Canberra: Australian Institute of Aboriginal Studies, 112-71.

Stigler, James W., Shweder, Richard A., and Herdt, Gilbert (eds.). 1990. Cultural Psychology: Essays on Comparative Human Development. Cambridge: Cambridge University Press.

Strauss, Claudia, and Quinn, Naomi. 1997. A Cognitive Theory of Cultural Meaning. Cambridge: Cambridge University Press.

SwEETSER, Eve. 1990. From Etymology to Pragmatics. Cambridge: Cambridge University Press.

Traugott, Elizabeth Closs, and Heine, Bernd (eds.). 1991. Approaches to Grammaticalization. Amsterdam: Benjamins.

TrUdGILl, PETER. 1997. 'Typology and sociolinguistics: Linguistic structure, social structure and explanatory comparative dialectology'. Folia Linguistica, 23.3-4: 349-60.

TugGY, DAvid. 1979. 'Tetelcingo Nahuatl'. In Ronald W. Langacker (ed.), Studies in UtoAztecan Grammar, ii: Modem Aztec Grammatical Sketches. Dallas: Summer Institute of Linguistics and University of Texas at Arlington, 1-140.

WASON, P. C., and REICH, C. C. 1979. 'A verbal illusion'. Quarterly Journal of Experimental Psychology, 31: 591-8.

WhoRf, Benjamin LeE. 1956. Language, Thought, and Reality. Cambridge, Mass.: MIT Press.

WIERZBicka, ANNA. 1979. 'Ethno-syntax and the philosophy of grammar'. Studies in Language, 3.3: 313-83.

-1988. The Semantics of Grammar. Amsterdam: John Benjamins.

—1991. Cross-Cultural Pragmatics: The Semantics of Human Interaction. Berlin: Mouton de Gruyter.

-1992. Semantics, Culture, and Cognition. New York: Oxford University Press.

-1997. Understanding Cultures Through Their Key Words. New York: Oxford University Press. 
WIERZBICKA, ANNA. 1998. Emotions Across Languages and Cultures: Diversity and Universals. Cambridge: Cambridge University Press.

WILKINS, David P. 1988. 'Switch-reference in Mparntwe Arrernte: form, function, and problems of identity'. In Peter Austin (ed.), Complex Sentence Constructions in Australian Languages. Amsterdam: John Benjamins, 141-76.

1991. 'The semantics, pragmatics and diachronic development of "Associated Motion" in Mparntwe Arrernte'. Buffalo Working Papers in Linguistics, 207-57.

1993. 'Linguistic evidence in support of a holistic approach to traditional ecological knowledge'. In G. N. Williams and G. Baines (eds.), Traditional Ecological Knowledge: Wisdom for Sustainable Development. Canberra: CRES Publications, 71-93.

Wolfram, WALt, and FASOLD, RALPH W. 1974. The Study of Social Dialects in American English. Englewood Cliffs, NJ: Prentice-Hall. 